\title{
Oportunidades y desafíos de la radio en la era digital
}

\author{
Adelaida Bolea de Anta \\ Universidad Complutense de Madrid \\ Pablo Ferrando García \\ Universitat Jaume I
}

En este número de adComunica, Revista Científica de Estrategias, Tendencias e Innovación en Comunicación, la sección Inform se ocupa de analizar el presente y pronosticar el futuro del medio radiofónico, en la convergencia digital.

La velocidad del cambio y las presiones comerciales que lo acompañan conducen a diferentes definiciones de radio digital, que según la plataforma o el soporte técnico puede significar diferentes cosas. Hablamos de radio digital cuando nos referimos al proceso por el cual una señal analógica se convierte en una señal digital, pero también hay definiciones mas amplias del concepto de digitalización que incluyen a las estaciones de radio que tienen web, la presencia en portales web, como las redes sociales, el streaming de audio, a través de redes IP fijas/inalámbricas para ordenadores personales o a través de redes UMTS a los teléfonos móviles (3G), las descarga de contenidos radiofónicos (podcast) o la presencia en otros dispositivos conectados como videoconsolas (IP).

Estos cambios significativos en el medio, han creado un oyente mas activo que genera sus propios contenidos multimedia, que exige dispositivos híbridos (que reciban la señal analógica, digital y las estaciones de Internet) y cada vez con una mayor calidad de audio.

La radio digital ha creado un escenario inédito y sus acomodos son los que se tratan de poner de manifiesto en las próximas páginas.

El catedrático de Comunicación Audiovisual y Publicidad de la Universidad de Santiago de Compostela Xosé Soengas analiza la necesidad de la redefinición de las funciones clásicas de los medios ante la evolución constante de una audiencia 
cada vez más segmentada y más exigente. Gracias a Internet, los contenidos de cualquier soporte están al alcance de los ciudadanos en cualquier momento y desde cualquier lugar. La radio convencional ha perdido su factor diferenciador: la instantaneidad y ahora tiene que adaptarse a la nueva realidad y competir con prensa y televisión desde sus páginas web.

Por su parte, Andrés Barrios Rubio, profesor y comunicador de la Universidad de Bogotá Jorge Tadeo Lozano nos aporta sus reflexiones en torno a los cambios en el entorno digital que se están experimentando en Colombia. Se parte del hecho cierto de que el ser humano de hoy está en un entorno de redes de comunicación y colaboración en el que se imponen modelos de sindicalización, afiliación, agregación y comunidades a través de portales, foros, blogs... Las audiencias dejaron de ser pasivas para convertirse en productoras de información, comunicación y contenidos, lo que lleva a una reformulación de los medios radiofónicos actuales para optimizar las herramientas y los mecanismos de intermediación e interactividad.

El cambio de roles en el desarrollo de la comunicación entre los medios de difusión y sus usuarios obliga a plantearse otra escala de valores para el intercambio de información directa, fragmentada, individualizada, interactiva, comunitaria y/o participativa. Estos cambios exigen profesionales que estén preparados para enfrentar los nuevos hábitos de consumo y se puedan desenvolver de manera apropiada en la nueva forma de expresividad (modelos de navegación, enlaces, adaptación de géneros, producción de contenidos). La Red permite crear nuevas estructuras, formatos, audiencias; es una época en la que, a través de la colaboración, se trata de reinventar el uso de los productos ya existentes. La plataforma es una herramienta del periodista. El problema es caer en el error de creer que las redes son el periodismo.

Los profesores de la Universidad Complutense de Madrid Adelaida Bolea y Rebeca Amieva de la Vega, y el investigador José María Huerta han hecho un balance panorámico del momento de la radio digital, en los países de nuestro entorno, tanto de la radio digital terrenal como de la radio desde Internet. Una vez acotado el concepto de digitalización han enumerado las cuestiones tecnológicas más importantes que deben abordarse en los posibles acuerdos internacionales. En este estudio, se enumeran las características tecnológicas más importantes para el asentamiento y evolución de la convergencia digital: el desarrollo de los receptores de radio híbridos (analógico-digitales) y el Euro-Chip como dispositivo idóneo. Las posibilidades digitales que se están imponiendo en el espectro de la radiodifusión, con el fin de alcanzar unos estándares técnicos óptimos de calidad, cambian los estándares de calidad. En este sentido, la familia DAB (Digital Audio Broadcasting) se erige, hasta ahora, en los estándares fundamentales de la emisión digital terrestre. La UE se está decantando por una difusión combinada entre redes terrestres y tecnología IP mediante la utilización de radios híbridas, es el caso del estándar de Radio DNS. Quizás el aspecto más interesante de esta tecnología sea el desarrollo de tres aplicaciones que 
introducen servicios de valor añadido a través de conexiones de Banda Ancha: RadioVIS, RadioEPG y RadioTAG.

Teresa Piñeiro-Otero y José Juan Videla, profesores de la Facultad de Comunicación Audiovisual en la Universidad de la Coruña, analizan la transformación del medio radio desde sus orígenes analógicos hasta el presente digital y aunque la radio ha perdido algunas de sus características clásicas como su fugacidad y su esencia exclusivamente sonora, ha estrechado la relación con su audiencia por medio de la adopción de nuevas formas de participación basadas en la interactividad. Partiendo de esta realidad, plantean su estudio sobre las potencialidades de la radio digital en España a través de la incorporación a los dispositivos portátiles (reproductores multimedia, smartphones, tablets, receptores digitales...).

En este sentido, el presente estudio ha tenido por objeto conocer la oferta de las aplicaciones para tablet y smartphone de las cadenas españolas, así como las posibilidades de participación que dichas APP ponen a disposición de los oyentes-usuarios. La oferta tecnológica está permitiendo un mayor proceso interactivo entre las emisoras y los oyentes, lo que está conduciendo a la personalización de los contenidos. Sin embargo, estas aplicaciones todavía ofrecen un acceso convencional a los contenidos radiofónicos obviando las posibilidades que brinda Internet y sobre todo a los dispositivos móviles, para la interacción continua e inmediata de usuarios y productores del medio. Frente a estas enormes ventajas y potencialidades tecnológicas y comunicativas los autores de este trabajo consideran que no existe aún en nuestro país una suficiente cultura de la portabilidad radiofónica, aunque vaticinan una gran trayectoria futura.

La periodista e investigadora Rosario Sacristán, junto a los profesores de la Universidad Complutense de Madrid Carmen Salgado y Miguel Ángel Ortiz, nos ofrecen los primeros resultados y conclusiones de un estudio de observación sobre las emisoras radiofónicas locales y regionales de Castilla y León, que han sabido acoplarse a las posibles ventajas de las nuevas tecnologías y estar presentes en Internet. Los autores echan de menos un sitio web de radio regional público o privado, con denominación de origen Castilla y León, con suficiente desarrollo de contenido informativo multimedia para que esta comunidad autónoma pudiera ser identificada desde fuera como una realidad autonómica diferenciada.

Las páginas que las cadenas de radio generalistas dedicaban en la web a las emisoras locales - contenidos de proximidad - eran pocas. La radio web especializada, local y regional, se nutría sobre todo de las páginas habilitadas por las emisoras comunitarias. En este contexto de crisis económica en el que los ingresos por publicidad descienden en todas las cadenas comerciales, la opción de aprovechar las páginas web locales para este fin no es descabellada. Nadie mejor que los gestores locales para conseguir publicidad en entornos siempre complicados, pero que conocen a la perfección. Las webs locales de radio, mu- 
chas de ellas infrautilizadas, deberían al menos, ofertar contenidos radiofónicos de proximidad adaptados a la web.

Javier García García, de Red de Medios Comunitarios (ReMC) de España, trata de delimitar el concepto de Radios Comunitarias, que se definen como radios de carácter no profesional ni lucrativo, con funcionamiento autogestionario, toma directa de decisiones, autonomía frente a grupos políticos, económicos y publicitarios, participación al servicio de la comunidad local y lucha contra el monopolio y centralización de la comunicación. A continuación, repasa la historia de las radios comunitarias, en España, en paralelo a la transformación del denominado Tercer Sector Audiovisual. A partir de ahí, explica el tratamiento que la legislación española ha dado a este fenómeno: Radios sin papeles, reparto de frecuencias, tratamiento de las radios sin ánimo de lucro y los incumplimientos de la Ley General de Comunicación Audiovisual.

Por último, detalla las oportunidades que la radio digital por ondas y la radio por Internet, puede tener para estas emisoras, en este sentido ya que las dificultades para emitir por FM o para lograr tener una amplia cobertura han dificultado enormemente el desarrollo de las radios comunitarias, que además se exponen a cierres o elevadas multas. Internet va a propiciar el desarrollo de proyectos informativos para distribución en red entre las radios libres y comunitarias del estado, contribuyendo al desarrollo de una nueva fase de coordinación. El autor pone de manifiesto que la incorporación a Facebook y Twitter, ha sido tardía, que muchos de los perfiles analizados presentan escasa o irregular actividad y no cuentan con grandes cifras de seguimiento. En comparación con otros medios alternativos las radios comunitarias tienen poca visibilidad en los nuevos espacios digitales. Con Internet ha aumentado el número de medios existentes pero también su fragmentación (muchos, pequeños y precarios) lo que no impide que en momentos cruciales, como los que están por llegar, este caótico sistema mediático ciudadano pueda tener un papel muy relevante.

\section{Referencia de este artículo}

Bolea de Anta, Adelaida y Ferrando García, Pablo (2013). Oportunidades y desafíos de la radio en la era digital. En: adComunica. Revista Científica de Estrategias, Tendencias e Innovación en Comunicación, ${ }^{\circ}$ 5. Castellón: Asociación para el Desarrollo de la Comunicación adComunica, Universidad Complutense de Madrid y Universitat Jaume I, 19-22. DOI: http://dx.doi.org/10.6035/2174-0992.2013.5.2 